\title{
Medication beliefs and use of medication lists - is there a connection? Results from a before-and-after study in Germany
}

\author{
Cornelia Straßner ${ }^{1 *}$, Cornelia Mahler ${ }^{2}$, Beate Strauß ${ }^{3}$, Ulrich Wehrmann ${ }^{4}$, Katja Krug$^{1}$, Joachim Szecsenyi ${ }^{1}$, \\ Walter Emil Haefeli ${ }^{5}$ and Hanna Marita Seidling ${ }^{5}$
}

\begin{abstract}
Background: Despite increasing digitalisation the paper-based medication list remains one of the most important instruments for the documentation and exchange of medication-related information. However, even elderly patients with polypharmacy who are at high risk for medication errors and adverse drug events, frequently do not receive or use a complete and comprehensible medication list. Increasing the use of medication lists would be a great contribution to medication safety and facilitate the work of health care providers.

Methods: This study is related to the project MeinPlan (MyPlan) which comprised an information campaign on safe drug administration in the Rhine-Neckar region in South Germany. The campaign was evaluated in a before-andafter study based on a survey among two independent, representative samples of citizens over 65 years. In total, 5034 questionnaires were analysed. While the effects of the primary outcome (the percentage of citizens using a medication list) have been reported elsewhere, this analysis focusses on the effects of the campaign on citizens' medication beliefs and assesses whether medication beliefs are associated with the use of medication lists, the use of over-the-counter drugs and the use of the tools offered by the campaign. Medication beliefs were assessed with the German version of the General Beliefs About Medicines Questionnaire (BMQ) which results in subscales for "General Overuse", "General Usefulness" and "General Harm". The use of medication lists and over-the-counter drugs was assessed with self-developed questionnaire items.
\end{abstract}

Results: No statistically significant change in citizens' medication beliefs before and after the campaign could be detected. Likewise, no association between medication beliefs and the use of medication lists, the use of over-thecounter drugs or the use of the tools offered by the campaign could be shown.

Conclusions: A campaign focussing on the risks of drug administration did not change the medication beliefs of the targeted population. Moreover, citizens' general medication beliefs do not seem to be crucial for their decision to use a medication list or over-the-counter drugs. Strategies to improve the use of medication lists by patients should focus on other influential factors, such as individual benefits and barriers and socio-psychological factors.

Keywords: Medication beliefs, Medication list, Medication reconciliation, Over-the-counter drugs, Behaviour change, Campaign

\footnotetext{
* Correspondence: cornelia.strassner@med.uni-heidelberg.de

${ }^{1}$ Department of General Practice and Health Services Research, University

Hospital Heidelberg, Im Neuenheimer Feld 130.3, 69120 Heidelberg,

Germany

Full list of author information is available at the end of the article
}

(c) The Author(s). 2020 Open Access This article is licensed under a Creative Commons Attribution 4.0 International License, which permits use, sharing, adaptation, distribution and reproduction in any medium or format, as long as you give appropriate credit to the original author(s) and the source, provide a link to the Creative Commons licence, and indicate if changes were made. The images or other third party material in this article are included in the article's Creative Commons licence, unless indicated otherwise in a credit line to the material. If material is not included in the article's Creative Commons licence and your intended use is not permitted by statutory regulation or exceeds the permitted use, you will need to obtain permission directly from the copyright holder. To view a copy of this licence, visit http://creativecommons.org/licenses/by/4.0/ The Creative Commons Public Domain Dedication waiver (http://creativecommons.org/publicdomain/zero/1.0/) applies to the data made available in this article, unless otherwise stated in a credit line to the data. 


\section{Background}

Prescribing medication is one of the most frequently applied measures to treat or prevent diseases. Across Europe, $31 \%$ of the older adults take 5 drugs or more per day [1]. With the number of prescribed drugs, the risk of hospitalisation due to adverse drug reactions, mainly falls, fractures, infections and bleedings, also increases [2]. Drug therapy is a complex and therefore error-prone process comprising the recommendation for a certain medication which should be based on the inventory of a patient's current medication as well as the assessment of the individual's preferences and needs, the writing of the prescription, the dispensing of the drug e.g. in a pharmacy, the application of the drug by the patient and the monitoring of the treatment effects [3].

In general, many persons and institutions are involved in this process. In Germany, adults over 60 years have an average of 11.9 ambulatory doctor's appointments per year contacting specialists in 4.2 different fields and spending, on average, 10.7 days in hospital each year [4]. Beside prescribers in inpatient and outpatient care, other professions, such as pharmacists, nurses as well as informal care givers, might also be involved in the process of care and drug administration.

To ensure efficient communication among all these players and to support patients in correct drug administration, timely, accurate and comprehensible documentation of the essential medication-related information is crucial. Despite ongoing attempts to establish electronic medical records, to-date, the paper-based medication list is the most common instrument for this purpose in Germany and in 2016 - 2 years after conduction of the MeinPlan (MyPlan) campaign - patients' right to receive a medication list became codified law.

However, not all patients on long-term medication have a medication list. If they do, discrepancies between the medication documented and the medication actually taken by the patients have been shown in over $70 \%$ of the cases [5-8] while 30\% of these discrepancies are also considered potentially harmful [9]. Furthermore, medication lists are frequently not available when needed because patients do not always carry them along or they use their own handwritten medication lists which lack important information or are illegible [10]. On the other hand, medication lists issued by health care professionals may not meet patients' needs because they list information relevant to other health care professionals rather than giving adequate information to facilitate patients' self-support. For instance, in a study examining patients' understanding of a medication list, 35\% of the participants were not satisfied with the design and 50\% misunderstood the abbreviations given on the list [11].

The aim of the project MeinPlan conducted by the "Aktionsbündnis Sichere Arzneimitteltherapie Heidelberg/
Rhein-Neckar" (Active Alliance for Safe Pharmacotherapy Heidelberg/Rhine-Neckar) was to raise awareness among the elderly population of the Rhine-Neckar region in South Germany about avoidable risks of drug treatment as well as possibilities for citizens to actively contribute to a safe drug treatment. Informing health care providers about the medication they actually take and avoiding administration errors were considered important contributions. Since an updated and comprehensible medication list is a useful tool for these purposes, the main objective was to increase the percentage of citizens on long-term medication using a medication list. The effects of the project were examined in a before-andafter study based on a representative survey.

According to the Health Belief Model [12], several factors influence the likelihood of engaging in a healthrelated behaviour. Figure 1 shows which strategies were used in the MeinPlan project and how they are related to the Health Belief Model. A major focus of the project was the citizens' perception of the risks coming with polypharmacy. Hence, we intended to raise awareness in this field. One hypothesis was that citizens' general medication beliefs influence their risk awareness and therefore their readiness to use a medication list or to engage in other medication-related health behaviours. The Beliefs About Medicine Questionnaire (BMQ) measures medication beliefs and distinguishes three dimensions: general harm, general usefulness and general overuse, ascertaining whether respondents believe medications to be generally rather harmful or useful and whether there is a general overuse of medication in the society. We assumed that citizens with a rather positive attitude towards medication use (i.e. generating high scores for general usefulness and low scores for general harm and general overuse) would be less risk-conscious and therefore less likely to use a medication list. In addition, we were interested whether the MeinPlan project had an influence on citizens' medication beliefs or not. Since we intended to raise awareness of the risks of polypharmacy, we assumed that the scores for general harm and general overuse might possibly raise.

While the descriptive results of the survey and the primary outcome of the study (percentage of citizens using a medication list) have been reported elsewhere [13], this article focusses on the following research questions:

1. Is there a difference regarding citizens' medication beliefs before and after the campaign of the project MeinPlan?

2. Does a correlation/association exist between citizens' medication beliefs and

2.1 ... the number of drugs taken? $2.2 \ldots$ the use of over-the-counter drugs? 2.3 ...the presence of a medication list? 2.4 ... the way the medication list is used? 


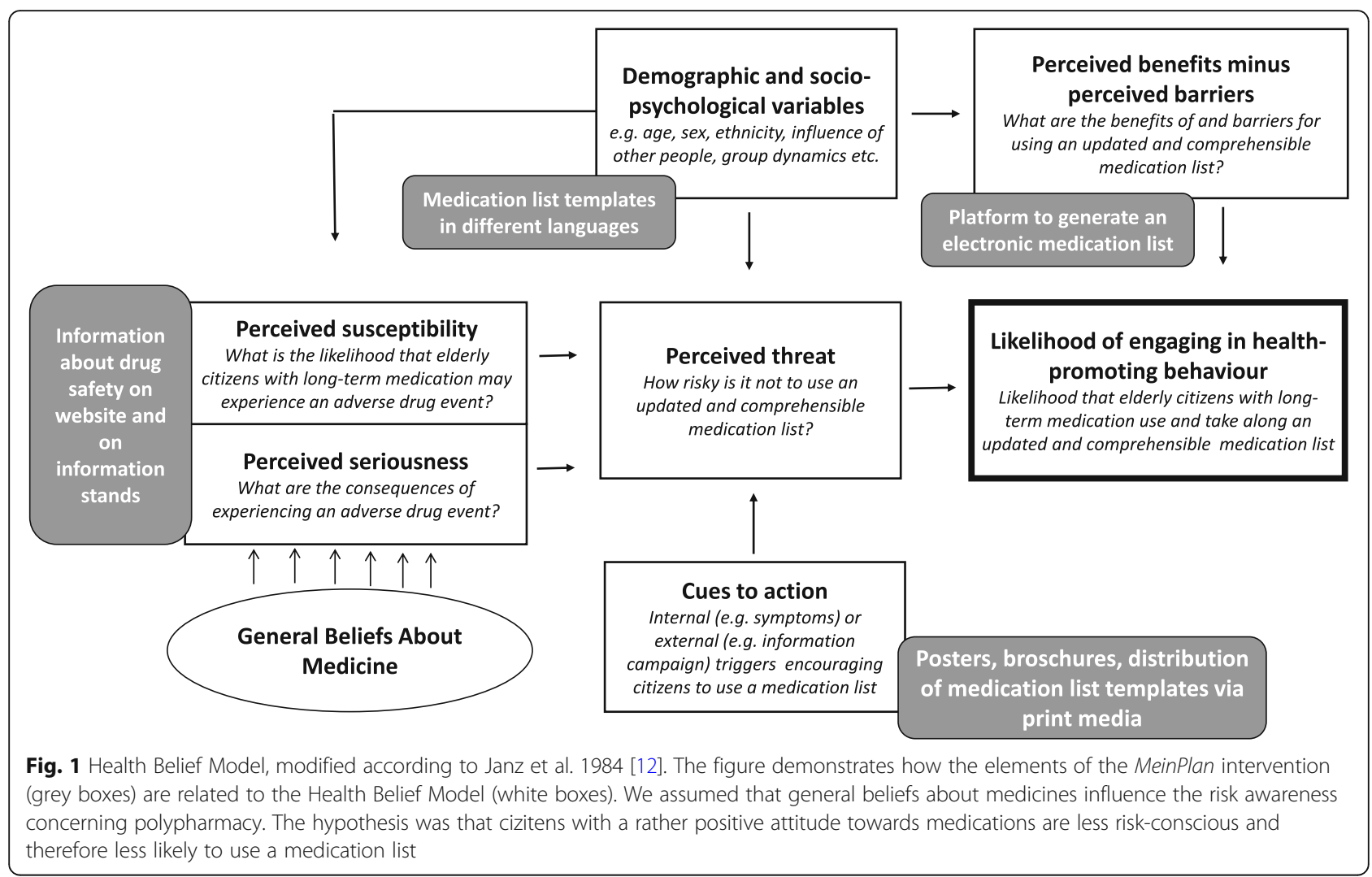

$2.5 \ldots$ the use of the tools (i.e. the website, the paper-based medication list template and the electronic medication list) offered by the project MeinPlan?

\section{Methods}

\section{Study design}

We conducted a non-randomised before-and-after study based on a written survey among two independent, representative samples of citizens aged over 65 years living in the Rhine-Neckar region of Southern Germany. The ethical approval was obtained from the responsible Ethics Committee of the Medical Faculty of Heidelberg University (number S-647/2013).

\section{Intervention}

Within the scope of the project MeinPlan, several population-based interventions were conducted between June 2014 and December 2015 with the aim to raise the public's and health care professionals' awareness for the risks of pharmacotherapy and thus the importance of medication lists and correct administration of medication. The campaign comprised the distribution of about 60.000 medication list templates via the local press. Lectures were held in adult education centres and during public events for senior citizens. The website www.nimmsrichtig.de contributed teaching videos about safe medication administration, enabled to download and print off medication list templates in different languages and provided access to an internet platform allowing to generate and manage an electronic medication list with illustrated administration advices. In addition, posters, flyers and brochures were distributed to pharmacies and general practitioners in the region. More details about the interventions have been depicted in the main report of the study [13].

\section{Participants and setting}

The target group of the survey were citizens aged 65 or above living in the Rhine-Neckar Region and the city of Heidelberg. The samples for the baseline and follow-up survey were independent, i.e. the individuals who participated in the first survey were excluded from the second one. Participants were randomly selected by an independent state institution. People living in a residential or nursing home were excluded by address.

\section{Variables}

The questionnaires used at baseline and follow-up were largely identical and consisted both of the German version of the General Beliefs About Medicine Questionnaire (BMQ General) $[14,15]$ and non-validated but pre-tested, self-developed items. The BMQ General assesses medication beliefs in general (not necessarily 
related to the medication of the individual respondent) and consists of 12 items which form 3 sub-scales: general harm, general usefulness and general overuse. All items are rated on a five-point Likert scale $(5=$ strongly agree, $1=$ strongly disagree). Sub-scale scores are calculated leading to values between 4 and 20. Higher scores indicate stronger belief in the respective concept, i.e. the general belief that there is an overuse of medication in the society and the general belief that medications are predominantly either harmful or useful. The German version of the $B M Q$ General has proven to be a valid and reliable instrument with high internal consistency [15].

Alongside socio-demographic data, the self-developed items collected information on the number of drugs respondents took regularly, by whom these drugs were recommended or prescribed (physician, pharmacist, other), whether or not the respondent had support with drug administration (yes/no), and whether and how he or she used a medication list (updated regularly, shown when visiting a doctor or a pharmacy, taken along during emergencies or used as a reminder). At followup, four additional questions related to the MeinPlan campaign were posed.

\section{Data collection}

Pseudonymised questionnaires were sent out by mail before the campaign started in June 2014 (T0) and after the end of the campaign in January 2016 (T1). To ensure confidentiality, the key for pseudonymisation was only available to the local health authority that organized the postal delivery of the questionnaires and not to Heidelberg University Hospital which received the responses and analysed the data. After 4 weeks, a reminder was sent. As an incentive, respondents were offered to participate in a price draw to win a book on medication administration.

\section{Sample size}

Power calculation was performed for the primary end point, the number of people with a medication schedule, yielding a sample size of 5340 citizens needed per time point. Given the population of the Rhine-Neckar-region and Heidelberg, this referred to about $4 \%$ of the population 65 years or older.

\section{Data analysis and statistical methods}

As a first step, descriptive analyses were conducted to describe the sample and to check for plausibility of the database. Implausible specifications mainly related to filter questions (respondents stating not to take any medication or not to have a medication list but answering all subsequent questions) were recoded and treated as missing values.

The t-test was used to determine the difference in medication beliefs as measured by the BMQ General at
T0 and T1 (research question 1). For correlation analyses (research questions 2.1-2.5) the data sets of T0 and T1 were pooled. The Eta coefficient was determined for correlations between interval-scaled and categorical variables and the Spearman coefficient for correlations between two ordinal variables and between ordinal and interval-scaled variables. $P$-values $<0.05$ were considered statistically significant, coefficients $>0.5$ were regarded clinically relevant correlations.

\section{Results \\ Participants}

We received 2640 questionnaires in the baseline survey (response rate 49.4\%) and 2427 questionnaires (response rate $45.4 \%$ ) in the follow-up survey after 18 months. In total, 33 questionnaires were excluded because 17 were not filled in and because in 16 other cases respondents were younger than 65 years according to the indicated year of birth. This resulted in a total sample size of 5034 respondents.

Table 1 shows the characteristics of the participants. On average, respondents were $75(65-101)$ years old with equal proportions of male (49.3\%) and female $(50.7 \%)$. The vast majority $(90.6 \%, N=4392)$ stated to take at least 1 drug regularly, $15.2 \%(N=739)$ reported extensive polypharmacy with more than 7 drugs. Concerning the medication beliefs, general usefulness averaged higher than general harm (16.1 / SD 2.48 versus 9.5 / SD 2.97) suggesting that the average population of the survey considered drugs in general more beneficial than harmful. The mean for general overuse was 13.0 (SD 3.11 ) indicating that the average population of the survey was undecided whether there was general overuse of drugs in the society or not.

\section{Main results}

Research question 1 focussed on whether there was a difference regarding the medication beliefs in the population before and after the MeinPlan campaign was conducted. The t-test showed no significant difference for all three sub-scales (see Table 2).

Table 3 shows the results of the correlation analyses. To answer research question 2.1, we examined whether there was an association between medication beliefs and the number of drugs regularly taken by the respondent. The Spearman correlation showed no clinically relevant relationship.

Research question 2.2 concentrated on the association between medication beliefs and the use of over-thecounter drugs (defined as drugs recommended by the pharmacists or bought in the supermarket without prescription). The Eta correlation coefficient showed no relevant correlation. 
Table 1 Characteristics of the participants and descriptive results [absolute numbers are previously reported in [13]]

\begin{tabular}{|c|c|c|c|}
\hline & T0 & T1 & $\mathrm{T} 0+\mathrm{T} 1$ \\
\hline Total population & $N=2609$ & $N=2425$ & $N=5034$ \\
\hline Age MEAN (RANGE) & $\begin{array}{l}73.9(65-101) \\
N=2577\end{array}$ & $\begin{array}{l}75.1(65-100) \\
N=2376\end{array}$ & $\begin{array}{l}74.5(65-101) \\
N=4953\end{array}$ \\
\hline Female PERCENTAGE (N/Ntotal) & $51.6(1334 / 2584)$ & $49.6(1182 / 2382)$ & $50.7(2516 / 4966)$ \\
\hline Non-native German speakers PERCENTAGE (N/Ntotal) & $3.8(96 / 2517)$ & $4.1(93 / 2273)$ & $3.9(189 / 4790)$ \\
\hline Population with regular medication intake PERCENTAGE (N/Ntotal) ${ }^{a}$ & $90.4(2288 / 2530)$ & $90.8(2107 / 2320)$ & $90.6(4395 / 4850)$ \\
\hline \multicolumn{4}{|l|}{ Number of medications taken } \\
\hline 0 & $9.6(242 / 2530)$ & $9.2(213 / 2320)$ & $9.4(455 / 4850)$ \\
\hline $1-3$ & $36.8(931 / 2530)$ & $36.8(853 / 2320)$ & $36.8(1784 / 4850)$ \\
\hline $4-7$ & $38.8(982 / 2530)$ & $38.3(890 / 2320)$ & $38.6(1872 / 4850)$ \\
\hline$>7$ & $14.8(375 / 2530)$ & $15.7(364 / 2320)$ & $15.2(739 / 4850)$ \\
\hline Use of over-the-counter drugs PERCENTAGE (N/Ntotal) ${ }^{b}$ & $27.7(631 / 2279)$ & $26.9(563 / 2095)$ & $27.2(1194 / 4371)$ \\
\hline $\begin{array}{l}\text { Having a medication list PERCENTAGE (N/Ntotal) referred to } \\
\text { all patients indicating regular drug intake }{ }^{\mathrm{a}}\end{array}$ & $51.6(1181 / 2288)$ & $51.4(1082 / 2107)$ & $51.5(2263 / 4395)$ \\
\hline \multicolumn{4}{|l|}{ Last medication list up-date $^{d}$} \\
\hline More than one year ago & $30.7(346 / 1127)$ & $33.0(345 / 1046)$ & $31.8(691 / 2173)$ \\
\hline Less than one year ago & $51.0(575 / 1127)$ & $51.0(533 / 1046)$ & $51.0(1108 / 2173)$ \\
\hline Never & $5.6(63 / 1127)$ & $4.4(46 / 1046)$ & $5.0(109 / 2173)$ \\
\hline Never because medication has not changed & $12.7(143 / 1127)$ & $11.7(122 / 1046)$ & $12.2(265 / 2173)$ \\
\hline $\begin{array}{l}\text { Documenting self-medication, i.e. additional drugs purchased in the pharmacy or in } \\
\text { the supermarket) on the medication list PERCENTAGE (N/Ntotal) }{ }^{c}\end{array}$ & $22.5(266 / 1181)$ & $21.6(234 / 1082)$ & $22.1(500 / 2263)$ \\
\hline Showing the medication list during doctor's appointments PERCENTAGE (N/Ntotal) ${ }^{a}$ & $35.3(417 / 1181)$ & $36.7(397 / 1082)$ & $36.0(814 / 2263)$ \\
\hline Showing the medication list in the pharmacy PERCENTAGE (N/Ntotal) ${ }^{a}$ & $2.5(29 / 1181)$ & $2.7(29 / 1082)$ & $2.6(58 / 2263)$ \\
\hline Taking the medication lists along for cases of emergency PERCENTAGE (N/Ntotal) ${ }^{a}$ & $56.6(669 / 1181)$ & $58.0(628 / 1082)$ & $57.3(1297 / 2263)$ \\
\hline Using the medication list as reminder PERCENTAGE (N/Ntotal) ${ }^{a}$ & $52.0(614 / 1181)$ & $55.2(597 / 1082)$ & $53,5(1211 / 2263)$ \\
\hline Not using the medication list at all PERCENTAGE (N/Ntotal) ${ }^{a}$ & $16.9(199 / 1181)$ & $14.9(161 / 1082)$ & $15.9(360 / 2263)$ \\
\hline $\begin{array}{l}\text { Having known the MeinPlan project before participating in the survey PERCENTAGE } \\
\text { (N/Ntotal) })^{\mathrm{a}}\end{array}$ & Not applicable & $5.7(139 / 2425)$ & Not applicable \\
\hline Having used the website www.nimmsrichtig.de PERCENTAGE (N/Ntotal) ${ }^{\text {a }}$ & Not applicable & $1.3(32 / 2425)$ & Not applicable \\
\hline $\begin{array}{l}\text { Having a used a medication list template provided by MeinPlan PERCENTAGE } \\
\text { (N/Ntotal) }{ }^{a}\end{array}$ & Not applicable & $1.0(25 / 2425)$ & Not applicable \\
\hline $\begin{array}{l}\text { Having used the electronic medication list provided by MeinPlan PERCENTAGE } \\
\text { (N/Ntotal) }^{a}\end{array}$ & Not applicable & $0.2(5 / 2425)$ & Not applicable \\
\hline BMQ subscale "General Overuse" MEAN (RANGE; SD) & $\begin{array}{l}13.0(4-20 ; 3.06) \\
N=2428\end{array}$ & $\begin{array}{l}12.9(4-20 ; 3.16) \\
N=2260\end{array}$ & $\begin{array}{l}13.0(4-20 ; 3.11) \\
N=4688\end{array}$ \\
\hline BMQ subscale "General Usefulness" MEAN (RANGE; SD) & $\begin{array}{l}16.1(4-20 ; 2.50) \\
N=2451\end{array}$ & $\begin{array}{l}16.0(4-20 ; 2.45) \\
N=2249\end{array}$ & $\begin{array}{l}16.1(4-20 ; 2.48) ; \\
N=4700\end{array}$ \\
\hline BMQ subscale "General harm” MEAN (RANGE; SD) & $\begin{array}{l}9.5(4-20 ; 2.98) \\
N=2377\end{array}$ & $\begin{array}{l}9.5(4-20 ; 2.95) \\
N=2193\end{array}$ & $\begin{array}{l}9.5(4-20 ; 2.97) \\
N=4570\end{array}$ \\
\hline
\end{tabular}

$N$ number, Ntotal number of total responses (differences to the total population are due to missing values)

$S D$ standard deviation

aDichotomous variable (response categories yes/no). Numbers refer to the response category "yes"

bichotomous variable (response categories yes/no) calculated by summation of the variable "Use of drugs recommended by pharmacists without prescription" and "Use of drugs bought by myself in the supermarket / drug store". Numbers refer to the response category "yes"

'Dichotomous variable (response categories yes/no) calculated by summation of the variable "I document medications bought in the pharmacy on my medication list" and "I document medications bought in the supermarket / drug store on my medication list". Numbers refer to the response category "yes"

Likewise, no relevant correlation was detected between medication beliefs and the existence of a medication list (research question 2.3) nor the way the medication list was used by the participants (research question 2.4), i.e. whether it was updated regularly, shown when visiting a doctor or a pharmacy, taken along during emergencies or used as a reminder. 
Table 2 Difference in the three sub-scales of the BMQ General between T0 and T1 (research question 1)

\begin{tabular}{llll}
\hline & $\begin{array}{c}p \text {-value } \\
(\mathrm{t} \text {-test) }\end{array}$ & Confidence Interval & Mean difference \\
\hline BMQ subscale "General Overuse" & 0.389 & $-0.100-0.256$ & 0.078 \\
BMQ subscale "General Usefulness" & 0.156 & $-0.039-0.244$ & 0.103 \\
BMQ subscale "General Harm" & 0.774 & $-0.147-0.197$ & 0.025 \\
\hline
\end{tabular}

Research question 2.5 examined whether individual medication beliefs influenced the use of the tools provided by the project MeinPlan, that is, the website, the paperbased medication list template and the electronic medication list. No relevant correlations could be detected.

\section{Discussion}

In this before-and-after study evaluating the project MeinPlan by means of representative surveys, no significant change in general medication beliefs among the target population could be shown. Equally, no statistical relationship between the population's general medication beliefs and medication-related behaviour, i.e. neither the use of over-the-counter drugs/extensive polypharmacy, nor the active use of a medication list or the use of the tools offered by the project, could be determined.

These findings are partly in line with and partly contradictory to the results of other studies. BMQ values in a German primary care setting have shown similar values for general overuse (11.7 points) and general harm (8.7 points) [15]. Other studies have also found, that medication beliefs do not change over (short) time

Table 3 Correlation analyses (research question 2.2-2.5)

\begin{tabular}{|c|c|c|c|c|}
\hline Theme in the questionnaire ${ }^{a}$ & & $\begin{array}{l}\text { BMQ subscale } \\
\text { "General Overuse" }\end{array}$ & $\begin{array}{l}\text { BMQ subscale } \\
\text { "General Usefulness" }\end{array}$ & $\begin{array}{l}\text { BMQ subscale } \\
\text { "General Harm" }\end{array}$ \\
\hline \multirow[t]{2}{*}{ Number of drugs taken } & $\mathrm{N}$ & 4564 & 4574 & 4449 \\
\hline & Spearman CC & -0.169 & 0.128 & -0.165 \\
\hline \multirow[t]{2}{*}{ Use of over-the-counter drugs } & N & 4124 & 4132 & 4020 \\
\hline & Eta CC & 0.043 & 0.040 & 0.027 \\
\hline \multirow[t]{2}{*}{ Existence of a medication list } & N & 4049 & 4060 & 3948 \\
\hline & Eta CC & 0.122 & 0.103 & 0.102 \\
\hline \multirow[t]{2}{*}{ Last medication list up-date } & $\mathrm{N}$ & 3740 & 3733 & 3647 \\
\hline & Eta CC & 0.121 & 0.096 & 0.093 \\
\hline \multirow[t]{2}{*}{ Documentation of self-medication on the medication list } & $\mathrm{N}$ & 2106 & 2124 & 2064 \\
\hline & Eta CC & 0.011 & 0.026 & 0.011 \\
\hline \multirow[t]{2}{*}{ Showing the medication list during doctor's appointments } & N & 2106 & 2124 & 2064 \\
\hline & Eta CC & 0.003 & 0.011 & 0.009 \\
\hline \multirow[t]{2}{*}{ Showing the medication list in the pharmacy } & N & 2106 & 2124 & 2064 \\
\hline & Eta CC & 0.071 & 0.039 & 0.054 \\
\hline \multirow[t]{2}{*}{ Taking the medication list along during emergencies } & N & 2106 & 2124 & 2064 \\
\hline & Eta CC & 0.036 & 0.049 & 0.020 \\
\hline \multirow[t]{2}{*}{ Use of the medication list as a reminder } & N & 2106 & 2124 & 2064 \\
\hline & Eta CC & 0.039 & 0.006 & 0.004 \\
\hline \multirow[t]{2}{*}{ No use of the medication list } & N & 2106 & 2124 & 2064 \\
\hline & Eta CC & 0.036 & 0.008 & 0.010 \\
\hline \multirow[t]{2}{*}{ Use of the website www.nimmsrichtig.de } & $\mathrm{N}$ & 2199 & 2188 & 2137 \\
\hline & Eta CC & 0.021 & 0.000 & 0.023 \\
\hline \multirow[t]{2}{*}{ Use of a medication list provided by the project MeinPlan } & N & 2196 & 2183 & 2131 \\
\hline & Eta CC & 0.010 & 0.034 & 0.016 \\
\hline \multirow[t]{2}{*}{ Use of the electronic medication list provided by the project MeinPlan } & N & 1412 & 1402 & 1369 \\
\hline & Eta CC & 0.027 & 0.001 & 0.017 \\
\hline
\end{tabular}

${ }^{\mathrm{a} C C}$ correlation coefficient, $N$ number 
[16]. However, in a similar survey conducted in the Swedish general population, general medication beliefs were in contrast to our findings strongly associated with medication-use-patterns: Respondents using prescription and/or over-the-counter drugs reported stronger positive beliefs about the benefits of drugs in general compared to those who did not [17]. The authors concluded that addressing general beliefs about medication in patient counselling may be important - this is in line with our original assumption.

In another study, beliefs about the specific medication taken by the patient (but not beliefs about medication in general) were identified as a predictor for the use of over-the-counter analgesics [18]. Not receiving a medication list at discharge from hospital was associated with higher concerns towards the medication in patients with ischaemic heart disease [19]. In a German study among elderly patients with multiple morbidities and polypharmacy, regular receipt of an updated medication list was associated with a higher perceived necessity to take one's specific medication. In addition, patients who found their medication list comprehensive had less concerns about their individual medication [20].

The results of this study have implications for the design of strategies intending to improve correct drug administration and the use of medication lists in the population. Our hypothesis was that addressing citizens' general medication beliefs is a crucial element in reaching this goal. Most of our strategies intended to raise awareness of the risks of pharmacotherapy and the fundamental necessity of meticulous documentation and correct and skilful drug application. Additionally, we provided tools to enable patients to create a comprehensive medication list on their own. This approach is in accordance with the Health Belief Model (Fig. 1) in which perceived threats have a major influence on the likelihood of engaging in a health-promoting behaviour [12]. However, the results of this study indicate that general medication beliefs are not a decisive factor in that matter. The scores of the BMQ General did not differ between respondents who reported using a high number of (over-the-counter) drugs or a medication list and those who did not.

We decided to measure general beliefs because our campaign focussed on the general risks of polypharmacy. Within the scope of a large, population-based campaign it would have been difficult and ethically questionable to provide information about specific drugs or individual therapeutic regimes. Yet it is possible that our findings would have been different if we had used the BMQ Specific Scale which measures patients' beliefs about the medications they actually take.

It is also possible that other aspects of the Health Belief Model, e.g. perceived benefits and barriers for the use of medication lists which we examined in another project [21] or socio-psychological factors are more relevant. Within the scope of large, population-based implementation programs such as MeinPlan, they could be addressed by designing a more benefit-oriented campaign instead of highlighting the risks of pharmacotherapy. It is possible that further strategies targeting individual barriers and involving social exchange, e.g. educational sessions in small groups or medication counselling in general practices and pharmacies, are necessary to actually change one's individual behaviour.

The results of this study also indicate that the cues to action provided by the project MeinPlan were not successful in modifying medication beliefs which might be due to the fact that only a small section of the population could be reached by the programme: only $6 \%$ of the respondents stated to have heard about the project before participating in the survey. Consequently, if population-based campaigns are planned, sufficient resources to guarantee a successful and vast outreach of the measures have to be budgeted, e.g. involving radio, television, and social networks [22].

Our findings are especially relevant in Germany, where recently, after the start of our project, a federal standard medication list was introduced by law. Since October 2016 all patients taking at least 3 long-term drugs have the right to receive a medication list and physicians are obliged to issue the federal medication list in their practices [11]. Yet 1 year after the law came into force, the dissemination of the federal standard medication list was still poor: a survey among 324 health insured individuals showed that only $37 \%$ of those prescribed more than 3 drugs had received the federal standard medication list. Only half of them had been asked whether they were taking additional over-the-counter drugs, $43 \%$ had not received instructions on how to use the medication list and $21 \%$ had not been informed about the purpose and the administration of their medication [23]. Consequently, effective strategies to increase the active use of the federal standard medication list by health care professionals and patients need to be developed and applied.

\section{Strengths and limitations}

The study was designed as an uncontrolled before-andafter study. Due to the absence of a control group, it remains unclear to which extent other factors not related to the intervention contributed to the fact that no effect of the campaign on medication beliefs could be shown.

The findings are based on a survey among a large, random sample which can be considered representative for the elderly German population at least in the RhineNeckar region. Even though the study used boosting methods to maximise response rates and prompted 
approximately half of the addressed audience to respond, there is still some inherent risk of selection bias [24].

The fact that international studies have shown a connection between medication beliefs and medication use pattern suggests that our findings are not necessarily transferable to other populations and countries.

While medication beliefs were measured by a validated instrument, all other items of the survey were selfdeveloped. So, the reliability and validity of the phenomena measured by these items remain unclear.

\section{Conclusions}

Our findings suggest that citizens' general medication beliefs are not crucial for their decision to use a medication list or over-the-counter drugs. Future projects intending to increase correct drug administration and dissemination of medication lists should not concentrate on this aspect, especially not exclusively on risks and threats. Other factors, such as perceived benefits and barriers as well as socio-psychological factors might be more relevant and should be explored in future research.

\section{Abbreviations}

BMQ General: German version of the general part of the Beliefs About Medicines Questionnaire; CC: Correlation coefficient; SD: Standard deviation; $\mathrm{N}$ : Number

\section{Acknowledgements}

The authors thank Bettina Brandeis for coordination of the sampling procedure, Christian Stock for statistical advice, Antje Miksch for intellectual contribution of the study protocol, Alexander Send for intellectual contribution to the e-medication list, Francesco Monteagudo for support in data management, and the Chamber of Pharmacists Baden-Württemberg and the Medical Chamber Nord-Baden for support of the project.

\section{Authors' contributions}

CS wrote the first draft of the manuscript, $C M, H S, U W, B S, J S, W E H$, and KK critically revised it. CM, HS, UW, BS, JS and WEH were responsible for conception and design of the study. CS and KK conducted the statistical analysis. UW organised the sampling procedure and the dispatch of the questionnaires. All authors read and approved the final version of the manuscript.

\section{Funding}

The project MeinPlan was funded by the "Kommunale Gesundheitskonferenz Rhein-Neckar-Kreis/Heidelberg" (Municipal Health Conference), AOK BadenWürttemberg, the Ministry of Social Affairs and Integration of BadenWürttemberg, and by the Klaus Tschira Stiftung $\mathrm{gGmbH}$. The funders were not involved into the design, analysis or reporting of the study.

\section{Availability of data and materials}

The datasets used and analysed during the current study are available from the corresponding author on reasonable request.

\section{Ethics approval and consent to participate}

The study was performed in accordance with the Declaration of Helsinki. Ethical approval was obtained from the Ethics Committee of the Medical Faculty of Heidelberg University (number S-647/2013). Since all data was collected anonymously, it was not necessary to obtain written informed consent. However, participants were informed that by returning the questionnaire they agree that their data will be analysed and published anonymously.

\section{Consent for publication}

Not applicable.

\section{Competing interests}

The authors declare that they have no competing interests.

\section{Author details}

${ }^{1}$ Department of General Practice and Health Services Research, University Hospital Heidelberg, Im Neuenheimer Feld 130.3, 69120 Heidelberg, Germany. ${ }^{2}$ Department of Nursing Science, University Hospital Tuebingen, Institute of Health Sciences, Hoppe-Seyler-Str. 9, 72076 Tuebingen, Germany. ${ }^{3}$ Berchelmann'sche Apotheke, Eberstädter Str. 63, 64319 Pfungstadt, Germany. ${ }^{4}$ OCM-Consult, Bayernstr. 56, 67061 Ludwigshafen, Germany. ${ }^{5}$ Department of Clinical Pharmacology and Pharmacoepidemiology, University Hospital Heidelberg, Im Neuenheimer Feld 410, 69120 Heidelberg, Germany.

Received: 30 May 2019 Accepted: 10 March 2020

Published online: 30 March 2020

\section{References}

1. Midao L, Giardini A, Menditto E, Kardas P, Costa E. Polypharmacy prevalence among older adults based on the survey of health, ageing and retirement in Europe. Arch Gerontol Geriatr. 2018;78:213-20.

2. Laatikainen $\mathrm{O}$, Sneck S, Bloigu R, Lahtinen M, Lauri T, Turpeinen M. Hospitalizations due to adverse drug events in the elderly-a retrospective register study. Front Pharmacol. 2016;7:358.

3. Bergert FW, Braun M, Ehrenthal K, Fessler J, Gross J, Huttner U, et al. Recommendations for treating adult and geriatric patients on multimedication. Int J Clin Pharmacol Ther. 2014;52(Suppl 1):1-64.

4. Rattay P, Butschalowsky H, Rommel A, Prutz F, Jordan S, Nowossadeck E, et al. Utilization of outpatient and inpatient health services in Germany: results of the German health interview and examination survey for adults (DEGS1). Bundesgesundheitsbl. 2013;56(5-6):832-44.

5. Aylward MJ, Rogers T, Duane PG. Inaccuracy in patient handoffs: discrepancies between resident-generated reports and the medical record. Minn Med. 2011;94(12):38-41.

6. Balon J, Thomas SA. Comparison of hospital admission medication lists with primary care physician and outpatient pharmacy lists. J Nurs Scholarsh. 2011;43(3):292-300.

7. Ekedahl A, Brosius H, Jonsson J, Karlsson H, Yngvesson M. Discrepancies between the electronic medical record, the prescriptions in the Swedish national prescription repository and the current medication reported by patients. Pharmacoepidemiol Drug Saf. 2011;20(11):1177-83.

8. Waltering I, Schwalbe O, Hempel G. Discrepancies on medication plans detected in German community pharmacies. J Eval Clin Pract. 2015;21(5): 886-92.

9. Tulner LR, Kuper IM, Frankfort SV, van Campen JP, Koks CH, Brandjes DP, et al. Discrepancies in reported drug use in geriatric outpatients: relevance to adverse events and drug-drug interactions. Am J Geriatr Pharmacother. 2009;7(2):93-104.

10. Freigofas J, Seidling HM, Quinzler R, Schottker B, Saum KU, Brenner H, et al. Characteristics of medication schedules used by elderly ambulatory patients. Eur J Clin Pharmacol. 2015;71(9):1109-20.

11. Botermann L, Krueger K, Eickhoff C, Kloft C, Schulz M. Patients' handling of a standardized medication plan: a pilot study and method development. Patient Prefer Adherence. 2016;10:621-30.

12. Janz NK, Becker MH. The health belief model: a decade later. Health Educ Q. 1984;11(1):1-47.

13. Seidling HM, Mahler C, Straßner C, Strauß B, Bernhard G, Szecsenyi J, Haefeli WE, Wehrmann U. Use of medication lists: a population-based approach to increase the prevalence of medication lists within a region in Germany - a pre-post study. Int J Clin Pharmacol Ther. 2019;57:375-83 (in press).

14. Horne R, Weinman J, Hankins M. The beliefs about medicines questionnaire: the development and evaluation of a new method for assessing the cognitive representation of medication. Psychol Health. 1999;14(1):1-24.

15. Mahler C, Hermann K, Horne R, Jank S, Haefeli WE, Szecsenyi J. Patients' beliefs about medicines in a primary care setting in Germany. J Eval Clin Pract. 2010;18(2):409-13.

16. Unni E, Shiyanbola OO, Farris KB. Change in medication adherence and beliefs in medicines over time in older adults. Glob J Health Sci. 2015;8(5):39-47.

17. Andersson Sundell K, Jonsson AK. Beliefs about medicines are strongly associated with medicine-use patterns among the general population. Int J Clin Pract. 2016;70(3):277-85. 
18. Pineles $L L$, Parente R. Using the theory of planned behavior to predict selfmedication with over-the-counter analgesics. J Health Psychol. 2013;18(12): 1540-9.

19. Allen LaPointe NM, Ou FS, Calvert SB, Melloni C, Stafford JA, Harding T, et al. Changes in beliefs about medications during long-term care for ischemic heart disease. Am Heart J. 2010;159(4):561-9.

20. Jager C, Steinhaeuser J, Freund T, Szecsenyi J, Goetz K. Medication lists and Brown bag reviews: potential positive and negative impacts on patients beliefs about their medicine. Biomed Res Int. 2015;2015:874067.

21. Straßner C, Steinhäuser J, Freund T, Szecsenyi J, Wensing M. German healthcare professionals' perspective on implementing recommendations about polypharmacy in general practice: a qualitative study. Fam Pract. 2018:35(4):503-10

22. Wakefield MA, Loken B, Hornik RC. Use of mass media campaigns to change health behaviour. Lancet. 2010;376(9748):1261-71.

23. Braun B. hkk Gesundheitsreport 2017 - Medikationsplan. https://www.hkk. de/infomaterial/hkk-gesundheitsreport\#hkkgesundheitsreport201 7medikationsplan. Last access 14.05.2019.

24. Berkg V, Gasse C, Schnell R, Haefeli WE. Mail surveys: obsolescent model or valuable instrument in general practice research? Swiss Med Wkly. 2005;135: 189-91.

\section{Publisher's Note}

Springer Nature remains neutral with regard to jurisdictional claims in published maps and institutional affiliations.

Ready to submit your research? Choose BMC and benefit from:

- fast, convenient online submission

- thorough peer review by experienced researchers in your field

- rapid publication on acceptance

- support for research data, including large and complex data types

- gold Open Access which fosters wider collaboration and increased citations

- maximum visibility for your research: over $100 \mathrm{M}$ website views per year

At BMC, research is always in progress.

Learn more biomedcentral.com/submissions 